\title{
Understanding vulnerability of agricultural production system to climatic stressors in North Indian Plains: a meso-analysis
}

\author{
Bishwa Bhaskar Choudhary ${ }^{1} \cdot$ Smita Sirohi $^{2}$
}

Received: 9 September 2020 / Accepted: 23 November 2021 / Published online: 7 January 2022 (c) The Author(s), under exclusive licence to Springer Nature B.V. 2021

\begin{abstract}
The present study has mapped the hot spots vulnerable to changing climate and identified the underlying driving indicators in subtropical Trans and Upper Gangetic plains (TUGP) of India. The long-term trends indicate that the area between latitude 25 and $28^{\circ} \mathrm{N}$ has been more exposed to adverse climatic changes especially rise in maximum summer/monsoon and minimum winter temperatures. The more predominant correlates of vulnerability in the region come not from the exposure to adverse meteorological conditions but from prevailing socio-economic conditions (adaptive capacity) and the increased environmental pressure (sensitivity). Among the top 40 most vulnerable districts in the TUGP, in about two-third, the exposure was at moderate to low level, but sensitivity was high and adaptive capacity very weak. Among the sensitivity indicators, the factor loadings, obtained through modified principal component technique, were high for average size of landholdings, Temperature Humidity Index load and productivity of paddy and wheat crops. Irrigation intensity, farm mechanization, cropping intensity, livestock density, proportion of milch animals stock, rural literacy rate and veterinary institutions were the critical factors in determining the adaptive capacity of a district. The study outlines range of research and policy imperatives for enhancing resilience of crop-livestock production system.
\end{abstract}

Keywords Exposure $\cdot$ Sensitivity $\cdot$ Crop-livestock production $\cdot$ THI Load

The article is based on the $\mathrm{PhD}$ thesis entitled "Climate Senstitivity of Agriculture in Trans and Upper Gangetic Plains of India:Potential Economic Impact and Vulnerability", submitted to ICAR-National Dairy Research Institute, Karnal (Haryana), India by the first author under the guidance of the second author in 2017.

Smita Sirohi

smitasirohi@yahoo.com

1 ICAR-Indian Grassland and Fodder Research Institute, Jhansi, Uttar Pradesh 284003, India

2 DESM Division, ICAR-National Dairy Research Institute, Karnal 132001, India 


\section{Introduction}

With mounting scientific evidence of climate change, building the resilience of the agriculture sector has become a priority agenda of development planning, especially in the tropical countries like India where the brunt of changing climate in anticipated to be high (Mendelsohn, 2006; IPCC, 2014). Since vulnerability is the flip side of resilience, in order to design and implement climate-resilient programmatic interventions, numerous studies have been conducted at macro, meso and micro levels for vulnerability assessment of various sectors to climate change (Berry et al., 2006; Bouroncle et al., 2017; Parker et al., 2019; Sehgal et al., 2013).

There is a great deal of methodological heterogeneity in the literature with respect to the approach followed for assessing vulnerability. Its conceptualization broadly consolidates around IPCC framework as stated in its Third Assessment Report. Vulnerability is defined as a function of the degree of exposure of the system to climatic hazards, its sensitivity to changes in climate and adaptive capacity. This approach has the advantage of integrating both the biophysical and socio-economic aspects and gives a more comprehensive assessment of vulnerability. Since the mid-2000s, a large number of studies have used the integrated approach to analyse the vulnerability of the agriculture sector and communities to climate change and variability in different regions of the world (Deressa et al., 2008; Etwire et al., 2013; Heltberg \& Bonch-Osmolovskiy, 2011).

Recent growth trends in Indian agriculture sector have shown its resilience to external shocks like COVID-19 pandemic. However, when it comes to susceptibility to climate shocks there is ample evidence to suggest that the agriculture sector in India is highly vulnerable (Auffhammer et al., 2012; Choudhary \& Sirohi, 2020). Given that India is the habitat for $17.7 \%$ of the world's population and it has the largest cultivated area in the world, the dimensions of agricultural vulnerability in this country have far-reaching implications for the global achievement of Sustainable Development Goals. Answers to questions like what is causing this system to be vulnerable and how is vulnerability distributed within the system are of paramount importance and need to be addressed with empirical firmness.

A number of studies have conducted the vulnerability profiling of districts in India at regional (Palanisami et al., 2008; Ravindranath et al., 2011; Sehgal et al., 2013; Tripathi, 2013) and national (O'Brien et al., 2004; Ramarao et al., 2016) level. The choice of indicators and coverage of a study have bearing on the outcome of vulnerability research and its policy relevance (Crane et al., 2017). For instance, for a vast and agro-climatically diverse country like India, vulnerability assessment covering all the 500+ districts in a single study conceals the crucial regional dimensions for policy planning as vulnerability is captured in relative terms. Similarly, in areas such as in Northern plains, where ownership of dairy animals is widespread and complements the rice- and wheat-based cropping systems as the basis of rural livelihoods (Erenstein et al., 2007), the adaptive capacity and sensitivity is conditioned by correlates of livestock farming - an aspect that has not been adequately considered in the available literature .

The approach to vulnerability in this study, while explicitly encompassing this aspect, conceptualizes vulnerability as the degree to which a system is prone and unable to cope with adverse effects of climate variability and changes (IPCC, 2007). Following the IPCC definition of vulnerability, which is most authoritative in the context of climate change, the present study uses an integrated approach to assess vulnerability as an outcome/state of being. The purpose of the paper is to answer some of the key questions related to the extent (how much), causes (why) and spatial distribution (where) of vulnerability. 


\section{Material and methods}

The Northern plains - a region well endowed in natural resources in terms of fertile soil and flow of perennial rivers, has been the seat of the Green Revolution in India. Two agroclimatic regions, viz., Trans and Upper Gangetic Plains (TUGP) from the Northern Plains (Fig. 1), comprising of 82 districts from the states of Punjab, Haryana, Uttar Pradesh and 2 districts from Rajasthan (neighbouring Punjab) cover an area of 26.6 million hectares formed the study area. Alarmed by the recent evidence on erratic precipitation and rising temperature in TUGP ( Mathison et al., 2013), estimates of 6.5-10.5 per cent loss in gross margin per hectare from crop due to rise in temperature (Choudhary \& Sirohi, 2020) and sensitivity of dairy animals to heat stress in the region, we have aggregated all the indicators and developed district wise vulnerability profile (since districts are the smallest administrative unit in India at which reliable agricultural data are available) across TUGP for making comparisons and effective adaptation planning.

\subsection{Selection of indicators}

The distinction between the indicators of exposure, sensitivity and adaptive capacity can sometimes be blur (Smit et al. 2006). Since sensitivity and adaptive capacity of a system are internal to it, selecting indicators for these two dimensions become relatively difficult and largely based on personal judgement (Kavi Kumar and Viswanathan, 2006). What constitutes each of these aspects of vulnerability is dependent upon the context of the question and pre-defined criteria. The indicators that determine the extent of the possible impact of

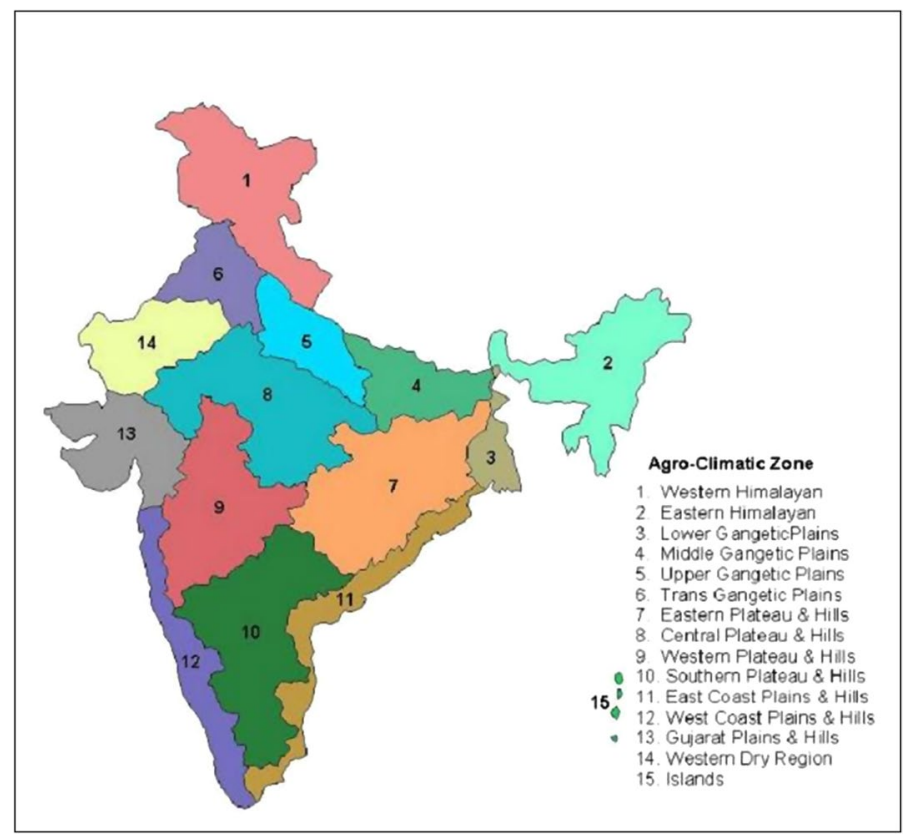

Fig. 1 Agro-climatic zones of India.

Map Source: https://vikaspedia.in/agriculture/crop-production/weather-information/agro-climatic-zones-in-india 
climate change and/or variability have been included in sensitivity. Likewise, under adaptive capacity we have selected those indicators that can be targeted to increase the resilience of the system through policy measures. Since the choice of indicators to be included in constructing an index involves some amount of subjectivity, this study relies on theoretical insights drawn from the literature reviewed in selecting indicators to minimize the subjectivity. A total of 32 indicators for the three components of vulnerability were taken (Table 1) and data for the latest year available at the time of conducting the study were used.

\subsubsection{Exposure}

Changes in two main climatic parameters, i.e., temperature and precipitation, over the years were taken as the indicators of exposure. Rate of change in maximum and minimum temperature, and coefficient of variation of precipitation during the two main cropping seasons in the region, viz., kharif (June-September) and rabi (October-February) over the period of 30 years (1980-2009) are observed. Further, in accordance with the definition given by the Indian Meteorological Department (IMD), the number of days having very heavy rainfall (124.5-244.5 $\mathrm{mm}$ ) and the number of days having extremely heavy rainfall (>244.5 mm) during 1980-2009 were also selected as indicators of exposure. As increasing trends in temperature and rainfall variability can have a negative impact on agriculture production system, a positive functional relationship of these indicators with vulnerability was hypothesized.

\subsubsection{Sensitivity}

While all the indicators of exposure led to increase in vulnerability, in case of the sensitivity indicators, the relationship with vulnerability was both positive and negative. Indicators such as higher cultivated area and concentration of population in rural areas were hypothesized to enhance the sensitivity of agricultural production system to potential climate stress; while larger size of land holding, higher productivity of major crops in the region (rice, wheat and sugarcane) and more organic carbon content of soil were hypothesized to decrease the sensitivity and hence, vulnerability. The typical evidence of a relationship between land holding size and agricultural productivity in the region (Sehgal et al., 2013) suggests that districts with smaller land holdings will be more climate sensitive as small holders face financial constraints in adopting an improved package of agricultural practices. Soil carbon improves the physical properties of soil, contributes to its structural stability and increases the cation exchange and water-holding capacity, thereby stimulating plant growth. Low organic carbon content of soils in a region hampers crop production and productivity and hence increases sensitivity and vulnerability of agriculture.

We introduce a new indicator in our analysis-THI load that has relevance for the sensitivity of livestock production. Temperature Humidity Index (THI) which incorporates combined effects of temperature and relative humidity is widely used to study climatic effects on livestock production (Choudhary \& Sirohi, 2019; Gantner et al., 2015; West et al., 2003). The data on weekly normals of maximum and minimum temperature and relative humidity from 103 stations in India were used to compute the weekly average THI based on the estimation method by Ravagnolo et al. (2000). The weekly THI load was then worked out at threshold THI of 72-beyond which the physiological functions of dairy animals get adversely affected (Upadhyay et al., 2007; Zewdu et al., 2014). Assuming the 


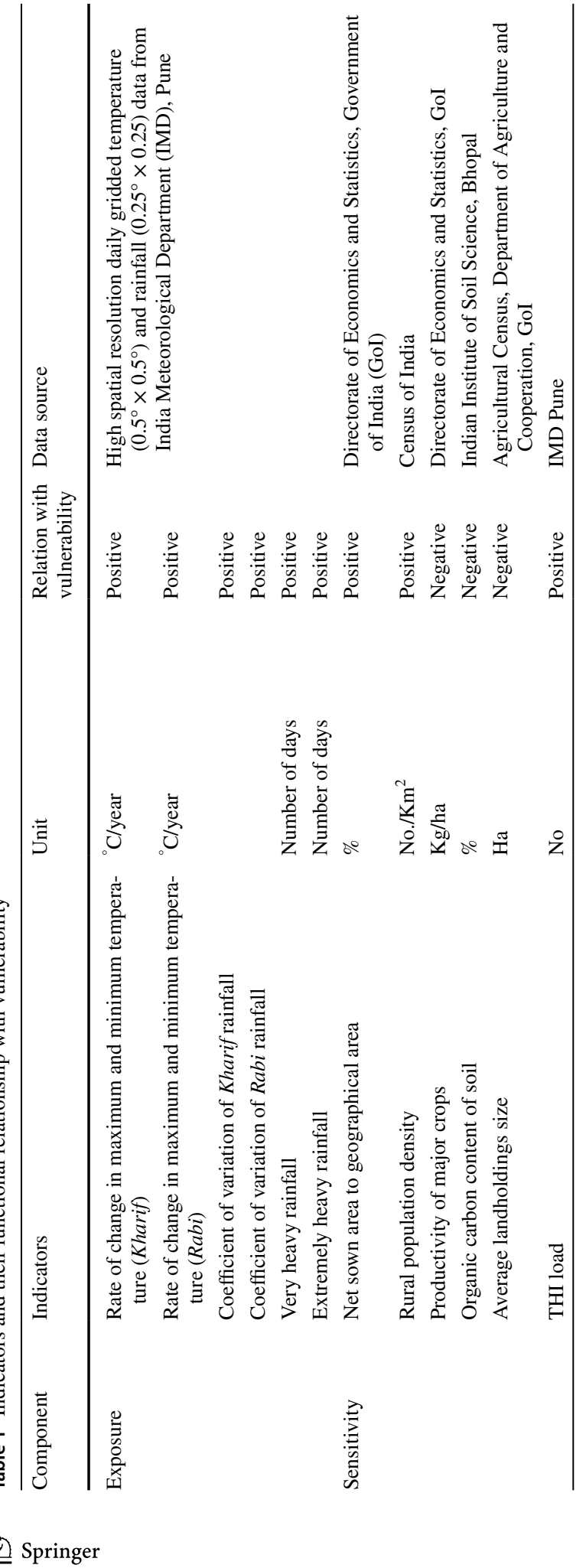




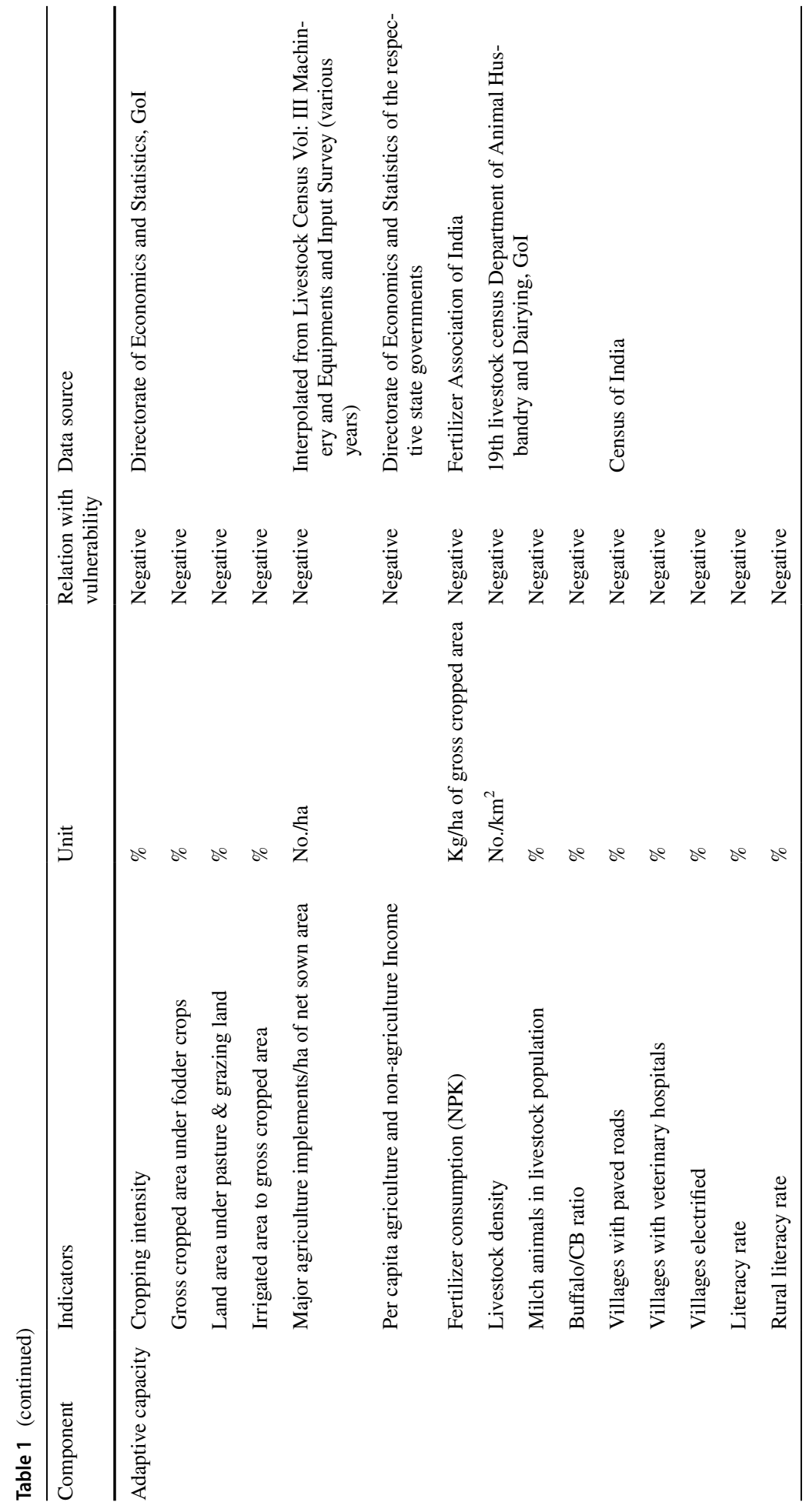


average weekly THI load to be uniform for all the seven days in the week, the total THI load in a week was computed as (Actual THI-72) * 7. The annual THI load is sum of the total weekly load over 52 weeks. At the district level, depending on the geographical coordinates of the estimates for the 103 stations, the appropriate value of the THI load was taken. Higher THI load based on climate normally implies that with increase in temperature, the heat stress in animals would aggravate, thus making the livestock production more sensitive to climate change.

\subsubsection{Adaptive capacity}

A total of sixteen indicators capturing physical, financial and human capital and infrastructure development of districts that help in withstanding the consequences of potential climate stresses were selected to represent adaptive capacity.

Education status of farmers has a bearing on their awareness about adverse impacts of climate change and also influences adoption of climate resilient agricultural practices. Therefore, literacy rate is hypothesized to be positively related with adaptive capacity. Higher percentage of area under assured irrigation, cropping intensity, area under fodder crops, pasture and grazing lands, livestock density and percentage of milch animal in livestock population along with ratio of buffaloes to crossbred are the resource endowment indicators of a district and therefore have positive functional relationship with adaptive capacity. Further, infrastructural facilities like veterinary hospitals, paved roads and electricity in villages strengthen the endurance capacity of a region against climate-related risks and thus are positively related with adaptive capacity. Finally, monetary strength of farm households represented by per capita income from agricultural and non-agricultural sources, and mechanization on farms in terms of agricultural implements used per hectare undoubtedly indicate good adaptive capacity.

\subsection{Normalization of variables}

As the indicators are measured in different units and scale, they are not additive. Therefore, they are to be converted into standard units to avoid any scale bias in final results. Various methods, viz., ranking, standardization (taking the deviation of each observation from its mean and then dividing it by its standard deviation), division by its length and division by its mean or any other ideal value, have been suggested in the literature to normalize the influence of units and scale. Though choice of any of these is not a value free decision, each has its own merits and demerits. In the present study, mean of each indicator was used for scale-free transformation of the data $\left(X_{j}^{*}=X_{i j} / \bar{x}_{j}\right)$ as it does not affect the dispersion of indicators and satisfies the basic axioms.

\subsection{Assigning weights to indicators}

Since all the indicators cannot be of equal importance in explaining the vulnerability, they need to be attached different weights. Some researchers make an arbitrary choice of assigning equal weights (O'Brien et al., 2004), other methods base it on expert judgement (Brooks et al., 2005; Moss et al., 2001), analytic hierarchy process (Sehgal et al., 2013), etc. These methods involve a high degree of subjectivity. A more extensively used objective approach to weighted indexing is principal component analysis (PCA) (Piya et al., 2012; Tripathi, 2013). PCA is a multivariate statistical technique used to reduce dimensionality 
by extracting the smallest number of components that account for most of the variation in the original multivariate data and by summarizing the data with little loss of information. The PCA approach gives higher weightages to indicators having higher correlations with other selected indicators. However, this approach does not account for the presence of substantial cross-sectional disparity among development variables. Therefore, we have used modified PCA (MPCA) technique (Majumder, 2005) to assign weights to indicators of each dimension of vulnerability. MPCA calculates the eigenvalues from the covariance matrix $\left(X^{*} X^{*} / n\right)$. This approach has methodological superiority over PCA as it rejects the correlation matrix as the basis for working out weights and the weights are calculated in such a manner that besides correlation, the disparities in distribution also have a role to play. MPCA ensures that indicators with greater variability get higher weights.

\subsection{Aggregation}

Before the aggregation of indices in the overall vulnerability index (VI), we compute subindices of exposure (EI), sensitivity (SI) and adaptive capacity (ACI). Each sub-index is constructed as weighted sum indicators. Various methods for aggregation of sub-indices point towards the same idea that vulnerability is a net of exposure, sensitivity and adaptive capacity. Following Antwi-agyei et al. (2012) and others, we compute the composite vulnerability index $(\mathrm{VI})=\mathrm{EI}+\mathrm{SI}-\mathrm{CI}$

\subsection{Classification of districts}

The districts were classified into 5 categories for each index using the Jenks optimization method in ARCGIS 10.0. Also known as Jenks natural breaks classification method, it is one of the data clustering methods designed to determine the best arrangement of values into different classes (de Smith et al., 2018). This method identifies logical break points in a data set by grouping similar values that "minimize differences between data values in the same class and maximize the differences between classes." It is specifically advantageous for making choropleth maps because it identifies real classes within the data.

\section{Results and discussion}

Representation of vulnerability with the single index brings an insight about the degree of vulnerability on a regional level and identifies the most vulnerable regions. However, to avoid simplistic policy conclusions based on the composite index (Gbetibouo et al., 2010; Saisana \& Tarantola, 2002) and fully assess the "big picture", presenting the indices of sub-components is useful (Zurovec et al., 2017).

\subsection{Components of vulnerability}

The use of factor loading corresponding to first principal component explaining the largest amount of information from the underlying data has been widely suggested (Filmer \& Pritchett, 2001; Gbetibouo et al., 2010; Poirier et al., 2020). In our data set, the first principal component explained about $64 \%$ of the total variation in exposure and adaptive 
capacity and about $78 \%$ in sensitivity (Appendix 1) and hence eigenvector associated with highest eigenvalue used as weights.

Rate of change in kharif (maximum temperature, very heavy rainfall) and rate of change in rabi (minimum temperature) have substantially contributed in inducing exposure across TUGP (Fig. 2a). The long-term trends substantiate a significant increase in kharif maximum temperature and rabi minimum temperature (Fig. 3). Districts located in southern parts of the TUGP (Mahamaya Nagar, Etawah, Auraiya, Mainpuri, Agra, Mathura and Firozabad) experienced comparatively higher rate of change in kharif maximum temperature $\left(0.016-0.026{ }^{\circ} \mathrm{C}\right.$ per year) and rabi minimum temperature $\left(0.047-0.052{ }^{\circ} \mathrm{C} /\right.$ year $)$ than the regional average of $0.010{ }^{\circ} \mathrm{C}$ and $0.041{ }^{\circ} \mathrm{C}$ per annum, respectively. Additionally, these districts also had higher number of days (8-16) with very heavier rainfall than the regional average of 5 days. Hence, the southern parts of the TUGP fall in extreme and high exposure category (Fig. 4a), while in most of the districts in eastern, central and western parts, the exposure levels are moderate to low. The districts in the northern parts of Punjab and Haryana, that are closer to the Himalayan region in India, are least exposed to temperature and rainfall changes and variability in the two agricultural season.

The factor loadings for average size of landholdings, THI load and productivity of major crops (rice and wheat) were higher among the sensitivity indicators (Fig. 2b), suggesting that both crop and livestock production system have a bearing on the vulnerability of rural

(a) Exposure Index

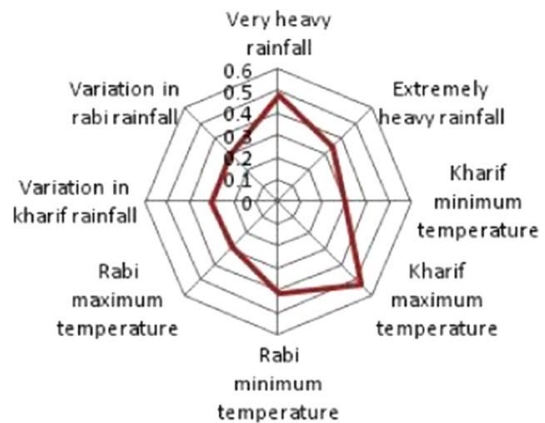

(b) Sensitivity Index

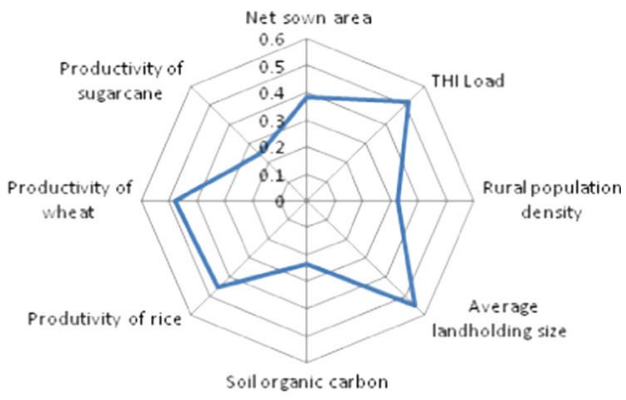

(c) Adaptive Capacity Index

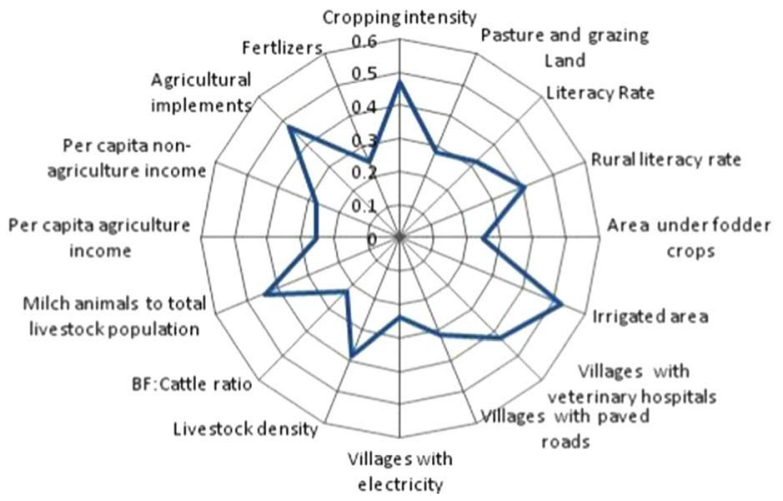

Fig. 2 Factor loadings of the vulnerability indicators 


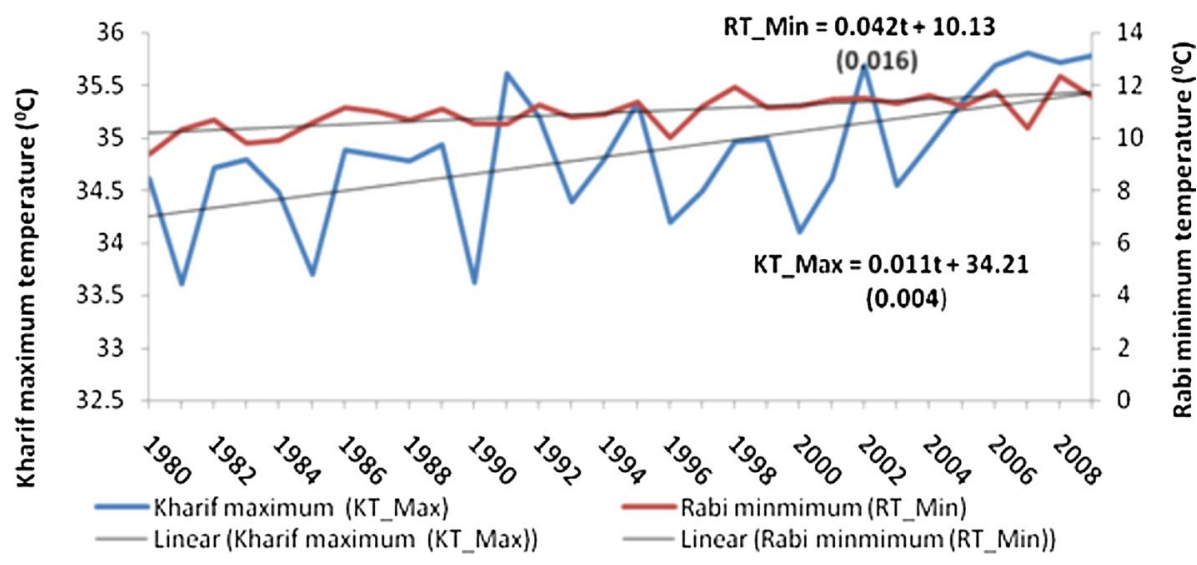

Fig. 3 Trends in kharif maximum and rabi minimum temperature in TUGP. Note: Figures in parentheses are standard errors

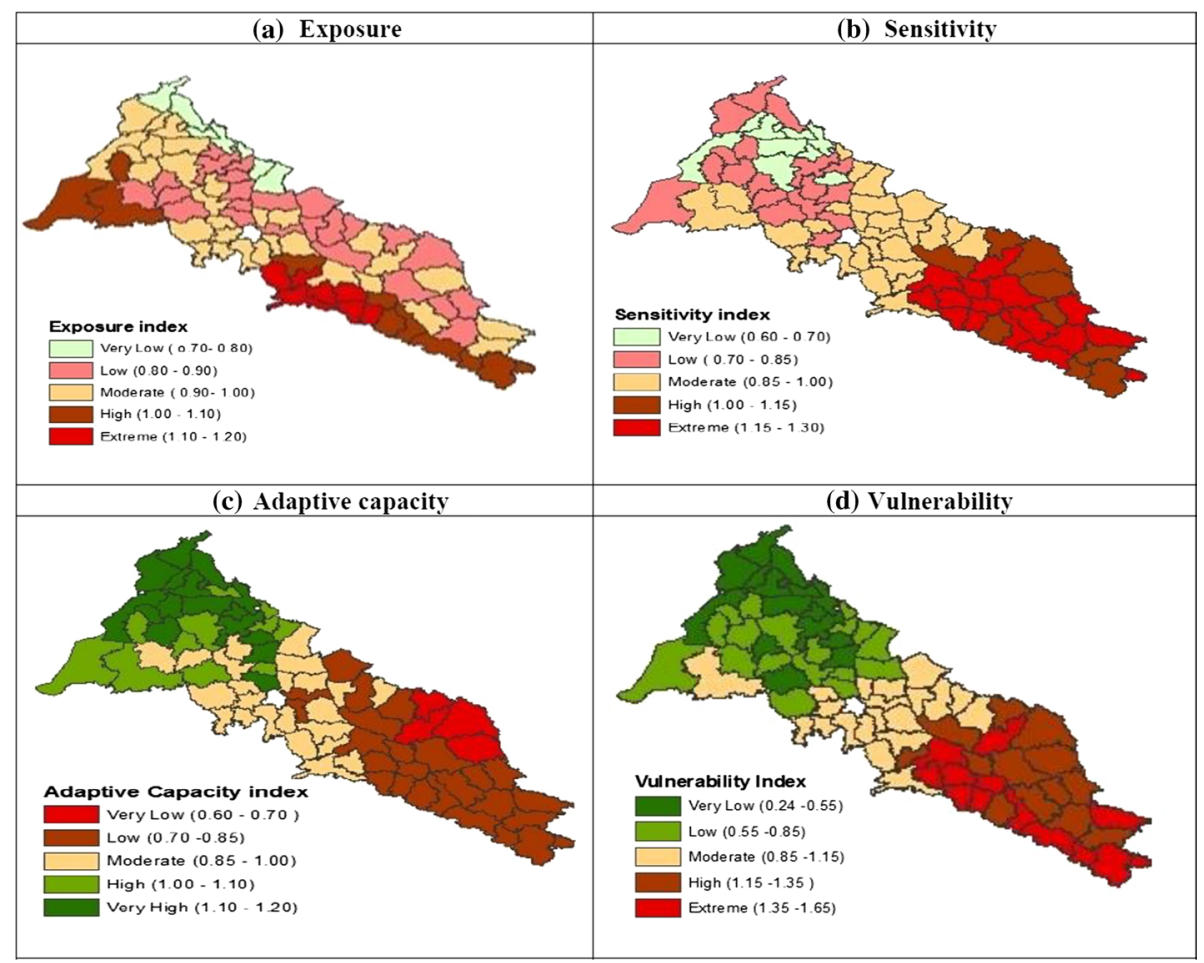

Fig. 4 Vulnerability profiling of districts across Trans and Upper Gangetic plains 
livelihoods. Sensitivity index for 84 districts varied widely ranging from a very low level of 0.60 (Fatehgarh Sahib) to extreme value of 1.28 (Rae Bareli) (Appendix 2). The eastern part of the region that compares unfavourably with the regional averages in the key indicators has been categorized as extreme and highly sensitive. Here, the average fam holding size is $0.42-0.68$ hectare (regional average 1.90 hectare); productivity of rice and wheat is about 1.8-1.9 tonnes/hectare and 2.1-2.7 t/ha, respectively, much lower than the average productivity of both the crops in TUGP (2.85 t/ha for rice and $3.67 \mathrm{t} / \mathrm{ha}$ for wheat). The hot humid climatic conditions cause higher THI load ranging from 1848 to 1920 units (regional average 1680), indicating that livestock, especially milk production, is very sensitive to heat stress. As we move from eastern to the central and western part of the region, a gradual decline in sensitivity is observable.

The critical factors (factor loading $>0.4$ ) determining the adaptive capacity of a district are irrigation intensity, farm mechanization, cropping intensity, livestock density, proportion of milch animals stock, rural literacy rate and veterinary institutions (Fig. 2c), The districts located in the north western part of the TUGP, falling in the state of Punjab, Haryana and western Uttar Pradesh, that typically have high irrigation and cropping intensity (Erenstein et al., 2007; Grover et al., 2017; Singh et al., 2012; Verma \& Singh, 2006), rank higher in terms of adaptive capacity index (Fig. 4c). Further, in these regions a comparatively higher rural literacy rate, higher proportion of milch animals and livestock density accentuate its adaptive capacity. Conversely, eastern districts of TUGP have very low to low adaptive capacity, largely due to low irrigation (51-68\%) and cropping (132-153\%) intensity and poor infrastructural endowment.

\subsection{Spatial distribution of vulnerability}

Vulnerability index for more than one-fourth (29\%) districts in the region was at extreme or high level, and, in one-fifth (20\%) same was on the other end in very low vulnerability category (Table 2). The vulnerability of the agriculture production system gradually increased as one moves from western to eastern parts across the TUGP (Fig. 4d). All the extreme and highly vulnerable districts fall in Upper Gangetic Plains (UGP), and the less vulnerable in the Trans-Gangetic plains. The higher resilience of agriculturally and infrastructurally better endowed states of Punjab and Haryana, and adjoining areas of western Uttar Pradesh has also been substantiated by other studies (Ramarao et al., 2016; Sehgal et al., 2013; Tripathi, 2013), using other methodological approaches.

Table 2 Number of districts in different vulnerability class in Trans and Upper Gangetic plains.

\begin{tabular}{lllllll}
\hline Regions & Total districts & \multicolumn{2}{l}{ Vulnerability class } \\
\cline { 3 - 7 } & & Extreme & High & Moderate & Low & Very low \\
\hline Upper Gangetic Plains & 41 & 13 & 11 & 14 & 3 & 0 \\
& & $(32)$ & $(27)$ & $(34)$ & $(7)$ & $(0)$ \\
Trans Gangetic Plains & 43 & 0 & 0 & 9 & 17 & 17 \\
& & $(0)$ & $(0)$ & $(20)$ & $(40)$ & $(40)$ \\
TUGP & $\mathbf{8 4}$ & $\mathbf{1 3}$ & $\mathbf{1 1}$ & $\mathbf{2 3}$ & $\mathbf{2 0}$ & $\mathbf{1 7}$ \\
& & $\mathbf{( 1 6 )}$ & $\mathbf{( 1 3 )}$ & $\mathbf{( 2 7 )}$ & $\mathbf{( 2 4 )}$ & $\mathbf{( 2 0 )}$ \\
\hline
\end{tabular}

Figures in parentheses are percentage of districts in different vulnerability class 
Table 3 Spearman's rank correlation coefficients

\begin{tabular}{llll}
\hline & Adaptive capacity index & Exposure index & Sensitivity index \\
\hline Adaptive capacity index & 1.000 & & \\
Exposure index & $-0.228 * *(-2.12)$ & 1.000 & \\
Sensitivity index & $-0.8715 *(-16.09)$ & $0.3243 *(3.10)$ & 1.000 \\
Vulnerability index & $-0.9058 *(-19.36)$ & $0.5114 *(5.38)$ & $0.9554 *(29.32)$ \\
\hline
\end{tabular}

(1) Figures in parentheses are t-ratios $(2) *$ and $* *$ indicate significance at $1 \%$ and $5 \%$ level, respectively

Strong negative rank correlation $(-0.91)$ between adaptive capacity and vulnerability index and positive correlation between sensitivity and vulnerability ranking in the study area (Table 3) highlight the importance of development and extension interventions for coping with climatic stressors. However, the rank correlation coefficient of exposure and vulnerability is of much lower magnitude, suggesting that vulnerability is not only induced

Table 4 Highly vulnerable districts: how exposed, sensitive and adaptive?

\begin{tabular}{lllll}
\hline Vulnerability level & Districts & Exposure level & Sensitivity level & $\begin{array}{l}\text { Adaptive } \\
\text { capacity } \\
\text { level }\end{array}$ \\
\hline & & & Low \\
\hline Extreme & Etawah & Extreme & Extreme & Low \\
& Auriya & Extreme & Extreme & Very low \\
& Shahjahanpur & Moderate & Extreme & Low \\
& Mainpuri & Extreme & Extreme & Low \\
& Kanpur City & High & Extreme & Low \\
& Fatehpur & High & Extreme & Low \\
& Kannauj & High & Extreme & Low \\
& S. R. Nagar & High & Extreme & Moderate \\
& Firozabad & Extreme & Extreme & Low \\
Sultanpur & Moderate & Extreme & Low \\
Kaushambi & High & High & Low \\
Allahabad & High & High & Low \\
& Etah & Moderate & Extreme & Low \\
Barabanki & Low & Extreme & Low \\
Kanpur Dehat & High & High & Low \\
Farrukhabad & Moderate & Extreme & Very low \\
Pilibhit & Low & High & Very low \\
Sitapur & Moderate & High & Low \\
Unnao & Moderate & Extreme & Low \\
Rae Barely & Low & Extreme & Low \\
Hardoi & Low & Extreme & Very low \\
Kheri & Low & High & Moderate \\
Mahamaya Nagar & Extreme & Moderate & Low \\
\hline Badaun & Low & High &
\end{tabular}


by climatic stress (as captured by exposure level) but it is a manifestation of multiple economic development factors.

The cross-classification of highly vulnerable (category extreme+ high) districts according to the level of exposure, sensitivity and adaptive capacity (Table 4) brings out this point more sharply. In a number of districts (Barabanki, Pilibhit, Rae Bareilly, Hardoi, Kheri and Badaun), despite low exposure to adverse temperature and rainfall conditions, lack of adaptive capacity coupled with high sensitivity makes them vulnerable to climatic stress. Among the top 40 most vulnerable districts in the TUGP (Appendix 2), in about 25, the exposure index was below 1.0 (viz., moderate to low level). On the other hand, districts like Muktsar, Sri Ganganagar and Hanumangarh have been able to develop strong coping mechanisms and hence are not highly susceptible to extreme exposure levels experienced by them.

\section{Conclusions}

The meso-level vulnerability profiling in the subtropical TUGP of India brings out that eastern part of this region is most vulnerable to climatic change, while the resilience improves gradually as one moves westward. Although the level of exposure to adverse changes in temperature and rainfall is geographically heterogeneous, yet broadly, the area lying between latitude $25-28^{\circ} \mathrm{N}$ is more susceptible to changing climate, especially rising maximum temperature in summer/monsoon (July-September) season and minimum temperature in winters (October-February).

The development of heat-tolerant cultivar, modifications in agronomic practices, e.g., adjustment in planting date to offset the risk of climatic exposure, promoting area under climate-smart crops like pulses and nutri-cereals, development of more accurate systems for early warning of extreme climatic events such as heavy rainfall, providing weatherbased crop and livestock advisory, developing low-cost precision agricultural and dairy farming techniques are some of the research and policy imperatives for coping with higher exposure levels in the subtropics. Integration of agro-forestry on farms can also go a long way in mitigating the detrimental effects of rising temperature (Dhyani et al., 2021; Inder et al., 2018).

Notwithstanding the relevance of measures to cushion against climatic exposure, the more predominant correlates of vulnerability in the TUGPs come not from the meteorological phenomenon as captured by exposure index, but from the prevailing socio-economic conditions (adaptive capacity) and the increased environmental pressure as a result of the human-environment interactions (sensitivity).

Small size of land holdings accentuates the sensitivity of the agricultural production system. The role of farm collectives can be crucial for enhancing the livelihood security of smallholders. In the past 7 years, the success of a number of Farmer Producer Organizations (FPOs) in the region provides useful learning lessons for replication of similar institutional model in other parts of the developing world. For improving sensitivity of the crop 
production system, enhancing the productivity of rice and wheat through dissemination of good agricultural practices is another vital area of extension focus. Augmenting resilience of dairy production to heat stress requires interventions targeted towards better housing, feeding and management of animals.

The role of agricultural infrastructure development in enhancing adaptive capacity is strikingly evident from the study. The access to assured irrigation and mechanization, two important factors that lead to exemplary agricultural growth popularly called Green Revolution in the western part of the TUGP, had limited spread in the other parts of the northern plains. Investment in irrigation holds the key in raising the cropping intensity in the central and eastern part of the region. Mechanizations of the farm operations on small-sized resource poor farm holdings do pose the challenge of economic viability requiring solutions such as agricultural implements custom hiring centres. This would also reduce the demand for draft animal power and shift the composition of bovine stock in favour of dairy animals. Supported by good health and breeding services, dairying can be an important means to build adaptive capacity of the smallholder farmers. Since rural literacy emerged to be an important component of adaptive capacity, mainstreaming practically oriented, participatory and interactive model like farmer field school (FFS) program to educate the farmers is another vital area of development planning.

Although the actual choice of interventions for reducing vulnerability would eventually depend on socio-economic factors prevailing in any region (Kumar et al., 2019), the evidence from northern Indian plains provides useful insights for setting research and policy agenda not only in the Indian context but also in other geographies in the sub-tropics where exposure to climatic change is anticipated to be similar.

\section{Appendix 1}

See Table 5 . 
Table 5 Factor scores from first principal component (PCA1) and associated statistics

\begin{tabular}{|c|c|c|c|c|}
\hline Component & Indicators & PCA1 & Eigenvalue & Proportion $(\%)$ \\
\hline \multirow[t]{8}{*}{ Exposure } & Rate of change in maximum Kharif temperature & 0.5344 & \multirow[t]{8}{*}{8.83} & \multirow[t]{8}{*}{63.71} \\
\hline & Rate of change in minimum Kharif temperature & 0.3050 & & \\
\hline & Rate of change in maximum Rabi temperature & 0.2917 & & \\
\hline & Rate of change in minimum Rabi temperature & 0.4162 & & \\
\hline & Coefficient of variation of Kharif rainfall & 0.3063 & & \\
\hline & Coefficient of variation of Rabi rainfall & 0.3020 & & \\
\hline & Very heavy rainfall & 0.4828 & & \\
\hline & Extremely heavy rainfall & 0.3528 & & \\
\hline \multirow[t]{8}{*}{ Sensitivity } & Net sown area to geographical area & 0.3824 & \multirow[t]{8}{*}{9.32} & \multirow[t]{8}{*}{77.72} \\
\hline & Rural population density & 0.3281 & & \\
\hline & Productivity of rice & 0.4512 & & \\
\hline & Productivity of wheat & 0.4758 & & \\
\hline & Productivity of sugarcane & 0.2416 & & \\
\hline & Organic carbon content of soil & 0.2337 & & \\
\hline & Average landholdings size & 0.5494 & & \\
\hline & THI load & 0.5143 & & \\
\hline \multirow[t]{16}{*}{ Adaptive capacity } & Cropping intensity & 0.4724 & \multirow[t]{16}{*}{16.44} & \multirow[t]{16}{*}{63.79} \\
\hline & Gross cropped area under fodder crops & 0.2473 & & \\
\hline & Land area under pasture \& grazing land & 0.2820 & & \\
\hline & Irrigated area to gross cropped area & 0.5238 & & \\
\hline & $\begin{array}{l}\text { Major agriculture implements / ha of net sown } \\
\text { area }\end{array}$ & 0.4751 & & \\
\hline & Per capita agriculture Income & 0.2514 & & \\
\hline & Per capita non-agriculture Income & 0.3709 & & \\
\hline & Fertilizer consumption (NPK) & 0.2475 & & \\
\hline & Livestock density & 0.3832 & & \\
\hline & Milch animals in livestock population & 0.4396 & & \\
\hline & Buffalo/CB ratio & 0.2302 & & \\
\hline & Villages with paved roads & 0.3140 & & \\
\hline & Villages with veterinary hospitals & 0.4283 & & \\
\hline & Villages electrified & 0.2375 & & \\
\hline & Literacy rate & 0.3238 & & \\
\hline & Rural literacy rate & 0.4042 & & \\
\hline
\end{tabular}

\section{Appendix 2}

See Table 6. 
Table 6 District wise rank and indices of vulnerability and its components

\begin{tabular}{|c|c|c|c|c|c|c|c|c|}
\hline \multirow[t]{2}{*}{ Districts } & \multicolumn{2}{|l|}{ Exposure } & \multicolumn{2}{|l|}{ Sensitivity } & \multicolumn{2}{|c|}{ Adaptive capacity } & \multicolumn{2}{|l|}{ Vulnerability } \\
\hline & index value & Rank & index value & Rank & index value & Rank & index value & Rank \\
\hline Etawah & 1.1478 & 3 & 1.2224 & 5 & 0.7218 & 80 & 1.6485 & 1 \\
\hline Auriya & 1.1404 & 5 & 1.2220 & 6 & 0.7604 & 77 & 1.6020 & 2 \\
\hline Shahjahanpur & 0.9726 & 25 & 1.2780 & 2 & 0.6952 & 81 & 1.5553 & 3 \\
\hline Mainpuri & 1.1447 & 4 & 1.2217 & 7 & 0.8399 & 62 & 1.5265 & 4 \\
\hline Kanpur City & 1.0803 & 10 & 1.1948 & 14 & 0.8176 & 70 & 1.4575 & 5 \\
\hline Fatehpur & 1.0727 & 11 & 1.2150 & 9 & 0.8429 & 58 & 1.4448 & 6 \\
\hline Kannauj & 1.0499 & 15 & 1.2102 & 10 & 0.8187 & 69 & 1.4414 & 7 \\
\hline Sant Ravidas Nagar & 1.0434 & 16 & 1.2096 & 11 & 0.8200 & 68 & 1.4330 & 8 \\
\hline Nagar Firozabad & 1.1020 & 7 & 1.1961 & 12 & 0.8930 & 51 & 1.4051 & 9 \\
\hline Sultanpur & 0.9682 & 30 & 1.2686 & 3 & 0.8426 & 59 & 1.3942 & 10 \\
\hline Kaushambi & 1.0303 & 18 & 1.1103 & 17 & 0.7570 & 78 & 1.3836 & 11 \\
\hline Allahabad & 1.0878 & 8 & 1.0864 & 20 & 0.7987 & 72 & 1.3755 & 12 \\
\hline Etah & 0.9193 & 44 & 1.1772 & 16 & 0.7364 & 79 & 1.3601 & 13 \\
\hline Barabanki & 0.8707 & 57 & 1.2536 & 4 & 0.7926 & 73 & 1.3316 & 14 \\
\hline Kanpur Dehat & 1.0668 & 13 & 1.0993 & 19 & 0.8398 & 63 & 1.3263 & 15 \\
\hline Farrukhabad & 0.9017 & 52 & 1.1863 & 15 & 0.7805 & 74 & 1.3074 & 16 \\
\hline Pilibhit & 0.8385 & 68 & 1.0825 & 21 & 0.6256 & 84 & 1.2954 & 17 \\
\hline Sitapur & 0.9179 & 45 & 1.0499 & 25 & 0.6782 & 83 & 1.2896 & 18 \\
\hline Unnao & 0.9060 & 51 & 1.2198 & 8 & 0.8414 & 60 & 1.2844 & 19 \\
\hline Rae Barely & 0.8309 & 72 & 1.2887 & 1 & 0.8404 & 61 & 1.2792 & 20 \\
\hline Hardoi & 0.8658 & 59 & 1.1951 & 13 & 0.8326 & 67 & 1.2284 & 21 \\
\hline Kheri & 0.8360 & 69 & 1.0603 & 23 & 0.6807 & 82 & 1.2156 & 22 \\
\hline Mahamaya Nagar & 1.1681 & 2 & 0.9715 & 30 & 0.9489 & 44 & 1.1907 & 23 \\
\hline Badaun & 0.8620 & 64 & 1.1049 & 18 & 0.7790 & 75 & 1.1879 & 24 \\
\hline Bareilly & 0.9717 & 27 & 0.9719 & 29 & 0.8096 & 71 & 1.1340 & 25 \\
\hline Agra & 1.1094 & 6 & 0.9809 & 27 & 0.9580 & 42 & 1.1323 & 26 \\
\hline Aligarh & 1.0677 & 12 & 0.9612 & 31 & 0.8968 & 50 & 1.1321 & 27 \\
\hline Pratapgarh & 0.9095 & 49 & 1.0568 & 24 & 0.8470 & 55 & 1.1193 & 28 \\
\hline Mewat & 0.9613 & 33 & 0.9821 & 26 & 0.8510 & 54 & 1.0924 & 29 \\
\hline Gurgaon & 0.9710 & 28 & 0.9737 & 28 & 0.8783 & 52 & 1.0664 & 30 \\
\hline Lucknow & 0.8136 & 76 & 1.0654 & 22 & 0.8394 & 64 & 1.0396 & 31 \\
\hline Mahendragarh & 0.9532 & 36 & 0.9124 & 40 & 0.8445 & 57 & 1.0211 & 32 \\
\hline Gautam Budhha Nagar & 0.9163 & 47 & 0.9325 & 35 & 0.8379 & 65 & 1.0109 & 33 \\
\hline Mathura & 1.1792 & 1 & 0.9103 & 43 & 1.0799 & 24 & 1.0096 & 34 \\
\hline Bijnor & 0.8660 & 58 & 0.9128 & 39 & 0.7761 & 76 & 1.0027 & 35 \\
\hline Gaziabad & 0.8744 & 55 & 0.9570 & 32 & 0.8457 & 56 & 0.9857 & 36 \\
\hline Bulandsahar & 0.9752 & 22 & 0.9511 & 34 & 0.9597 & 40 & 0.9666 & 37 \\
\hline Rewari & 0.9785 & 19 & 0.9551 & 33 & 0.9849 & 32 & 0.9487 & 38 \\
\hline Moradabad & 0.8208 & 74 & 0.9318 & 36 & 0.8355 & 66 & 0.9171 & 39 \\
\hline Rampur & 0.8327 & 71 & 0.9308 & 37 & 0.8571 & 53 & 0.9064 & 40 \\
\hline Palwal & 0.9591 & 34 & 0.8810 & 48 & 0.9410 & 46 & 0.8991 & 41 \\
\hline Bagpat & 0.9270 & 43 & 0.9305 & 38 & 0.9590 & 41 & 0.8986 & 42 \\
\hline Faridabad & 0.9721 & 26 & 0.8904 & 47 & 0.9718 & 35 & 0.8907 & 43 \\
\hline
\end{tabular}


Table 6 (continued)

\begin{tabular}{|c|c|c|c|c|c|c|c|c|}
\hline \multirow[t]{2}{*}{ Districts } & \multicolumn{2}{|l|}{ Exposure } & \multicolumn{2}{|l|}{ Sensitivity } & \multicolumn{2}{|c|}{ Adaptive capacity } & \multicolumn{2}{|l|}{ Vulnerability } \\
\hline & index value & Rank & index value & Rank & index value & Rank & index value & Rank \\
\hline Meerut & 0.9296 & 41 & 0.9111 & 42 & 0.9535 & 43 & 0.8872 & 44 \\
\hline Jhajjar & 0.9777 & 20 & 0.8109 & 57 & 0.9190 & 49 & 0.8696 & 45 \\
\hline Rohtak & 0.9278 & 42 & 0.8786 & 50 & 0.9378 & 47 & 0.8687 & 46 \\
\hline Hanumangarh & 1.0569 & 14 & 0.8955 & 45 & 1.0861 & 22 & 0.8662 & 47 \\
\hline Muzzafarnagar & 0.8609 & 65 & 0.9053 & 44 & 0.9232 & 48 & 0.8430 & 48 \\
\hline Amroha & 0.8954 & 54 & 0.9113 & 41 & 0.9688 & 37 & 0.8379 & 49 \\
\hline Bhiwani & 0.9142 & 48 & 0.8791 & 49 & 0.9616 & 39 & 0.8317 & 50 \\
\hline Sriganganagar & 1.0307 & 17 & 0.8492 & 55 & 1.0728 & 29 & 0.8071 & 51 \\
\hline Muktsar & 1.0830 & 9 & 0.7958 & 60 & 1.0898 & 20 & 0.7891 & 52 \\
\hline Jind & 0.9541 & 35 & 0.7951 & 61 & 0.9694 & 36 & 0.7799 & 53 \\
\hline Sirsa & 0.8355 & 70 & 0.8952 & 46 & 0.9683 & 38 & 0.7624 & 54 \\
\hline Kaithal & 0.9066 & 50 & 0.7397 & 68 & 0.9747 & 33 & 0.6716 & 55 \\
\hline Moga & 0.9741 & 23 & 0.7847 & 64 & 1.1097 & 14 & 0.6491 & 56 \\
\hline Panipat & 0.8217 & 73 & 0.8747 & 51 & 1.0508 & 31 & 0.6457 & 57 \\
\hline Saharanpur & 0.7385 & 82 & 0.8500 & 54 & 0.9483 & 45 & 0.6403 & 58 \\
\hline Bhatinda & 0.9625 & 31 & 0.7993 & 59 & 1.1270 & 12 & 0.6347 & 59 \\
\hline Fatehabad & 0.8649 & 62 & 0.7389 & 69 & 0.9735 & 34 & 0.6303 & 60 \\
\hline Sonipat & 0.8654 & 60 & 0.8455 & 56 & 1.1023 & 17 & 0.6086 & 61 \\
\hline Faridkot & 0.9468 & 38 & 0.7701 & 67 & 1.1320 & 9 & 0.5849 & 62 \\
\hline Ambala & 0.8716 & 56 & 0.7846 & 65 & 1.0742 & 27 & 0.5820 & 63 \\
\hline Sangrur & 0.9688 & 29 & 0.6795 & 79 & 1.0682 & 30 & 0.5800 & 64 \\
\hline Panchkula & 0.7799 & 79 & 0.8703 & 52 & 1.0794 & 25 & 0.5707 & 65 \\
\hline Tran Taran & 0.9521 & 37 & 0.7131 & 71 & 1.1020 & 18 & 0.5632 & 66 \\
\hline Yamunagar & 0.7816 & 78 & 0.8512 & 53 & 1.0757 & 26 & 0.5571 & 67 \\
\hline Amritsar & 0.9616 & 32 & 0.7005 & 73 & 1.1126 & 13 & 0.5495 & 68 \\
\hline Hisar & 0.8540 & 66 & 0.7871 & 63 & 1.0928 & 19 & 0.5483 & 69 \\
\hline Barnala & 0.9419 & 39 & 0.6801 & 78 & 1.0810 & 23 & 0.5410 & 70 \\
\hline Mansa & 0.8181 & 75 & 0.7839 & 66 & 1.0895 & 21 & 0.5125 & 71 \\
\hline Karnal & 0.8963 & 53 & 0.7993 & 58 & 1.1864 & 4 & 0.5091 & 72 \\
\hline Firozpur & 0.9741 & 24 & 0.6119 & 83 & 1.1410 & 8 & 0.4449 & 73 \\
\hline Kurukhetra & 0.8641 & 63 & 0.6877 & 75 & 1.1084 & 16 & 0.4434 & 74 \\
\hline Patiala & 0.8522 & 67 & 0.7161 & 70 & 1.1285 & 11 & 0.4398 & 75 \\
\hline Ludhiana & 0.9386 & 40 & 0.6595 & 80 & 1.1932 & 1 & 0.4048 & 76 \\
\hline Jallandhar & 0.9759 & 21 & 0.6139 & 82 & 1.1864 & 5 & 0.4034 & 77 \\
\hline Kapurthalla & 0.9171 & 46 & 0.6539 & 81 & 1.1867 & 3 & 0.3843 & 78 \\
\hline SAS Nagar & 0.7825 & 77 & 0.6821 & 77 & 1.1084 & 15 & 0.3562 & 79 \\
\hline Nawasahar & 0.7385 & 81 & 0.6859 & 76 & 1.0732 & 28 & 0.3513 & 80 \\
\hline FG Sahib & 0.8653 & 61 & 0.6020 & 84 & 1.1310 & 10 & 0.3362 & 81 \\
\hline Hoshiarpur & 0.7122 & 84 & 0.7938 & 62 & 1.1898 & 2 & 0.3162 & 82 \\
\hline Ropar & 0.7669 & 80 & 0.6929 & 74 & 1.1485 & 7 & 0.3113 & 83 \\
\hline Gurudaspur & 0.7214 & 83 & 0.7051 & 72 & 1.1828 & 6 & 0.2438 & 84 \\
\hline
\end{tabular}


Supplementary Information The online version contains supplementary material available at https://doi. org/10.1007/s10668-021-01997-7.

\section{Declarations}

Conflict of interest The authors declare that they have no relevant or material financial interests that relate to the research described in this paper.

\section{References}

Antwi-Agyei, P., Fraser, E. D. G., Dougill, A. J., Stringer, L. C., \& Simelton, E. (2012). Mapping the vulnerability of crop production to drought in Ghana using rainfall, yield and socioeconomic data. Applied Geography, 32, 324-334.

Auffhammer, M., Ramanathan, V., \& Vincent, J. R. (2012). Climate change, the monsoon, and rice yield in India. Climatic Change, 111, 411-424.

Berry, P. M., Rounsevell, M. D. A., Harrison, P. A., \& Audsley, E. (2006). Assessing the vulnerability of agricultural land use and species to climate change and the role of policy in facilitating adaptation. Environmental Science \& Policy, 9, 189-204.

Bouroncle, C., Imbach, P., Rodríguez-Sánchez, B., Medellín, C., Martinez-Valle, A., \& Läderach, P. (2017). Mapping climate change adaptive capacity and vulnerability of smallholder agricultural livelihoods in Central America: Ranking and descriptive approaches to support adaptation strategies. Climatic Change, 141, 123-137.

Brooks, N., Adger, W. N., \& Kelly, P. M. (2005). The determinants of vulnerability and adaptive capacity at the national and the implications for adaptation. Global Environmental Change, 15, 151-162.

Choudhary, B. B., \& Sirohi, S. (2019). How sensitive are buffaloes (Bubalus bubalis) to heat stress? Journal of Dairy Research, 86(4), 399-440.

Choudhary, B. B., \& Sirohi, S. (2020). Modelling climate sensitivity of agriculture in trans and upper gangetic plains of India. Theoretical and Applied Climatology, 142, 381-391.

Crane, T. A., Delaney, A., Tamás, P. A., Chesterman, S., \& Ericksen, P. (2017). A systematic review of local vulnerability to climate change in developing country agriculture. Wires Climate Change, 8(e464), 1-21.

Grover, D. K., Singh, J. M., Kaur, A., \& Kumar, S. (2017). State Agricultural Profile- Punjab, AERC Study No. 44, Punjab Agricultural University, Ludhiana.

de Smith, M. J., Goodchild, M. F., Longley, P. A., \& Associates. (2018). Geospatial analysis: a comprehensive guide to principles techniques and software tools. Retrieved from https://www.spatialana lysisonline.com/extractv6.pdf

Deressa, T., Hassan, R. M., \& Ringler, C. (2008). Measuring Ethiopian farmers' vulnerability to climate change across regional states. IFPRI Discussion Paper 00806.

Dhyani, S., Murthy, I. K., Kadaverugu, R., Dasgupta, R., Kumar, M., \& Adesh Gadpayle, K. (2021). Agroforestry to achieve global climate adaptation and mitigation targets: Are South Asian countries sufficiently prepared? Forests, 12, 303.

Verma, S. R., \& Singh, S. (2006). Long-term strategies and programmes for mechanization of agriculture in agro climatic zone-VI: Trans-Gangetic plains region. Retrieved from http://www.farmech. dac.gov.in/06035-04-ACZ6-15052006.pdf

Erenstein, O., Thorpe, W., Singh, J., \& Varma, A. (2007). Crop-livestock interactions and livelihoods in the Indo-Gangetic Plains, India: A regional synthesis. Mexico, D.F.: CIMMYT.

Etwire, P. M., Al-Hassan, R. M., \& Osei-Owusu, Y. (2013). Application of livelihood vulnerability index in assessing vulnerability to climate change and vulnerability in Northern Ghana. Journal of Environment and Earth Science, 3(2), 157-170.

Filmer, D., \& Pritchett, L. H. (2001). Estimating wealth effect without expenditure data or tears: An application to educational enrollments in states of India. Demography, 38(115), 32.

Gantner, V., Mijic, P., Kuterovac, K., Barac, Z., \& Potocnik, K. (2015). Heat stress and milk production in the first parity Holsteins- threshold determination in eastern Croatia. Poljoprivreda, 21, 97-100.

Gbetibouo, G. A., Ringler, C., \& Hassan, R. (2010). Vulnerability of the South African farming sector to climate change and variability: An indicator approach. Natural Resources Forum, 34, 175-187.

Heltberg, R., \& Bonch-Osmolovskiy, M. (2011). Mapping vulnerability to climate change. World bank policy research working paper 5554, Social development unit, The World Bank. 
Inder, D., Ram, A., Bhaskar, S., \& Chaturvedi, O. P. (2018). Role of Agroforestry in current scenario. Agroforestry for climate resilience and rural livelihood (pp. 1-10). Jodhpur, India: Scientific Publishers.

IPCC. (2007). IPCC fourth assessment report: Climate change (AR4). IPCC, Geneva, Switzerland.

IPCC. (2014). Climate change 2014: Impacts, adaptation, and vulnerability. part b: regional aspects. contribution of working group II to the fifth assessment report of the intergovernmental panel on climate change [Barros, V. R., Field, C.B., Dokken, D.J., Mastrandrea, M.D., Mach, K.J., Bilir, T.E., Chatterjee, M., Ebi, K.L., Estrada, Y.O., Genova, R.C., Girma, B., Kissel, E.S., Levy, A.N., MacCracken, S., Mastrandrea, P.R., \& White, L.L. (eds.)]. Cambridge University Press, Cambridge, United Kingdom and New York, NY, USA, pp. 688.

Singh, J., Grover, D. K., \& Dhaliwal, T. K. (2012). State agricultural profile - PUNJAB. AERC study No. 30. Retrieved from http://www.aercpau.com/assets/docs/Punjab\%20Profile.pdf

Kavi kumar, K. S. and Viswanathan B (2006) vulnerability to globalization in India relative rankings of states using fuzzy models. Research Paper No. 2006/40, World institutes for Development Economics Research.

Kumar, A., Sirohia, S., Pandey, D., Devi, R. H., \& Choudhary, B. B. (2019). Gross economic efficiency of water use in agriculture and water-saving farm plans for Punjab. Agricultural Economics Research Review, 32, 43-53.

Mathison, C., Wiltshire, A., Dimri, A., Falloon, P., Jacob, D., Kumar, P., Moors, E., Ridley, J., Siderius, C., Stoffel, M., \& Yasunari, T. (2013). Regional projections of North Indian climate for adaptation studies. Science of the Total Environment, 468-469, S4-S17.

Mendelsohn, R., Dinar, A., \& Williams, L. (2006). The distributional impact of climate change on rich and poor countries. Environment and Development Economics, 11, 159-178.

Moss, R. H., Brenkert, A. L., \& Malone, E. L. (2001). Vulnerability to climate change: A quantitative approach. Research report prepared for the U.S. Department of Energy, September.

O’Brien, K., Leichenko, R., Kelkar, U., Venema, H., Aandahl, G., Tompkins, H., Javed, A., Bhadwal, S., Barg, S., Nygaard, L., \& West, J. (2004). Mapping vulnerability to multiple stressors: Climate change and economic globalization in India. Global Environment Change, 14(4), 303-313.

Palanisami, K., Raganathan, C., Senthilnathan, S., \& Umetsu, C. (2008). Developing the composite vulnerability index relating to climate change for the different agro climatic zones of Tamil Nadu. Interuniversity Research Institute Corporation, National Institute for the Humanities, Research Institute for Humanity and Nature, Japan, Pp 127-137. ISBN:978-4-902325-28-7.

Parker, L., Bourgoin, C., Martinez-Valle, A., \& Laderach, P. (2019). Vulnerability of the agricultural sector to climate change: the development of a pan-tropical climate risk vulnerability assessment to inform sub-national decision making. PLOS ONE, 14(3), e0213641.

Piya, L., Maharjan, K. L., \& Joshi, N. P. (2012). Vulnerability of rural households to climate change and extremes: analysis of chepang households in the mid-hills of Nepal. Selected Paper prepared for presentation at the International Association of Agricultural Economists (IAAE) Triennial conference, Foz do Iguaçu, Brazil, pp.18-24.

Poirier, M. J. P., Grépin, K. A., \& Grignon, M. (2020). Approaches and alternatives to the wealth index to measure socioeconomic status using survey data: A critical interpretive synthesis. Social Indicators Research, 148, 1-46.

Majumder, R. (2005). Infrastructure and regional development: Interlinkages in India. Indian Economic Review, 40(2), 167-184.

Ramarao, C. A., Raju, B. M. K., Subbarao, A. V. M., Rao, K. V., Rao, V. U. M., Ramachandran, K., Venkateswarlu, B., Sikka, A. K., Srinivasa Rao, M., Maheswari, M., \& Srinivasa Rao, Ch. (2016). A district level assessment of vulnerability of Indian agriculture to climate change. Current Science, 110(10), 1939-1946.

Ravagnolo, O., Misztal, I., \& Hoogenboom, G. (2000). Genetic component of heat stress in dairy cattle, development of heat index function. Journal of Dairy Science, 83, 2120-2125.

Ravindranath, N. H., Rao, S., Sharma, N., Nair, M., Gopalakrishnan, R., Rao, A. S., Malaviya, S., Tiwari, R., Sagadevan, A., Munsi, M., Krishna, N., \& Bala, G. (2011). Vulnerability Profiles for North East India. Current Science, 101(3), 384-394.

Saisana, M., \& Tarantola, S. (2002). State-of-the-Art report on current methodologies and practices for composite indicator development; European commission, Joint Research Centre: Ispra, Italy.

Sehgal, V. K., Singh, M. R., Chaudhary, A., Jain, N. \& Pathak, H. (2013). Vulnerability of agriculture to climate change: district level assessment in the Indo-Gangetic plains. Indian Agricultural Research Institute, New Delhi, pp, 74.

Smit, B., \& Wandel, J. (2006). Adaptation, adaptive capacity and vulnerability. Global Environmental Change, 16, 282-292. 
Tripathi, A. (2013). Farmers' vulnerability to climate change in Uttar Pradesh, India: measurement and correlates. Institute of Economic Growth, New Delhi. Retrieved from www.ecoinse.org/lib_docs.

Upadhyay, R. C., Singh, S. V., Kumar, A., Gupta, S. K., \& Ashutosh (2007). Impact of climate change on milk production of murrah buffaloes. Italian. Journal of Animal Science, 6 (2), 1329-1332.

West, J. W., Mullinix, B. G., \& Bernard, J. K. (2003). Effects of hot, humid weather on milk temperature, dry matter intake, and milk yield of lactating dairy cows. Journal of Dairy Science, 86, 232-242.

Zewdu, W., Thombre, B. M., \& Bainwad, D. V. (2014). Effect of macro-climatic factors on milk production and reproductive efficiency of Holstein Friesian $\times$ Deoni crossbred cows. Journal of Cell and Animal Biology, 8(4), 51-60.

Žurovec, O., Cadro, S., \& Sitaula, B. K. (2017). Quantitative assessment of vulnerability to climate change in rural municipalities of Bosnia and Herzegovina. Sustainability, 9, 1208.

Publisher's Note Springer Nature remains neutral with regard to jurisdictional claims in published maps and institutional affiliations. 